\title{
EL ESTADO SOCIAL DE DERECHO EN COLOMBIA: PERTINENCIA Y VIGENCIA
}

Semillero ådscrito al Grupo Nuevas Visiones del Derecho, categoría B de Colciencias. Scholla está Integrado por los estudiantes Esteban Ordóñez Benavides, Luis Fernando Pacheco Gutiérrez, Cristiañ "Camilo Correa Flórez, Martín Eduardo Salazar Medina, Viviana Pinto Rondon y Gina Viviana Navarro Bastidas.

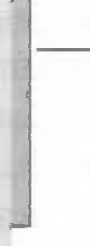

\section{RESUMEN}

Se presenta el papel que ha desempeñado la figura del Estado Social de Derecho y en concreto las instituciones que cambiaron su rumbo a partir de 1991; para tal fin se esbozará lo que la doctrina internacional llama Estado Social de Derecho así como su desarrollo al interior del sistema jurídico colombiano y de ésta manera responder al interrogante de si ha sido necesario un cambio en los elementos del Estado Social de Derecho que traía originalmente la carta de 1991 a través de las reformas constitucionales cursadas en el Congreso a lo largo de estos 15 años.

\section{ABSTRACT}

It's displayed therole that the Social state or Right has carried out and in particular the institutions that changed their course from 1991; for such aim it will be outlined what the doctrine has called Social State of right as well as his development to the interior of the Colombian Legal System and of this way answer the question of if a change in the elements that the Social State of Right brought originally in the letter of 1991 through the constitutionals changes in the Congress throughout this 15 years has been necessary.

\section{PALABRAS CLAVES}

Estado Social de Derecho - Pertinencia - Vigencia - Sistema Jurídico Colombiano - Doctrina internacional - Constitución - Acción de Tutela.

\section{KEYWORDS}

Social state of Right - Relevancy - Validity - Colombian Juridical System - international Doctrine - Constitution - Action of it Guides. 


\section{INTRODUCCIÓN}

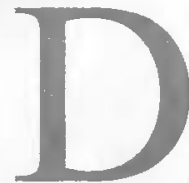

entro de la celebración que se ha llevado a cabo con ocasión de la promulgación de la Constitución Política de Colombia en 1991, es necesario hacer un alto en el camino y hacer un analisis critico con el fin de responder las preguntas que la comunidad socio jurídica se ha formulado con relación al papel que la constitución ha cumplido en estos 15 años: ¿Ha sido pertinente la adopción de la fórmula "Estado Social de Derecho" como estrella polar del accionar Estatal? ¿Ha colmado las expectativas sociales que se le imputaron al nuevo régimen? ¿La eficacia del Estado Social de Derecho en Colombia ha estado a la altura de las necesidades de los asociados?

Estas y muchas otras preguntas giran en torno al verdadero significado y respectiva puesta en práctica del Estado Social de derecho en Colombia; por tanto el semillero de investigación socio jurídica SCHOLLA busca que con ésta investigación se pueda arrojar un diagnóstico claro, coherente y acorde a la realidad nacional sobre la tarea que ha desempeñado ésta figura y en concreto las instituciones que cambiaron su rumbo a partir de 1991 en relación al que hacer cotidiano de la sociedad colombiana.

\section{DESARROLLO DEL ESTADO SOCIAL DE DERECHO}

La fórmula "Estado Social de Derecho" adoptada por nuestra constitución encierra un inmenso bagaje histórico, de tal forma que para acuñar el concepto ha sido necesario recurrir a los más grandes sucesos en el proceso historiográfico humano y encontrándonos con dos clases de elementos que la fundan, como lo son unos elementos internos y unos elementos externos.

Los primeros, es decir, los elementos internos bajo la óptica del derecho y social, refiriéndonos en ambos casos como un determinado momento del Estado. Es así como el ESTADO de DERECHO, que como es conocido por todos, responde a un postulado de LIBERTAD a través de un presupuesto fundamental cual es la dignidad de la persona; un presupuesto de DERECHO cual es el principio de racionalidad significando que el humano como novedad única e irrepetible utiliza su magnificencia para crear un sistema de resolución de conflictos que utiliza la racionalidad humana y deriva en el Derecho; un presupuesto de limitación del poder o prohibición del absolutismo, y por último, un presupuesto de la ley o principio de la voluntad general, por cuanto el órgano encargado de la legislación en Colombia adquiere su legitimidad en la voluñtad popular representada en un voto.

Como características de ese Estado de Derecho, heredadas directamente de las luchas históricas (como la revolución francesa en 1789) y constituciones o cartas magnas (comola otorgada en 1215 por Juan sin tierra), encontramos un imperio de la ley, una división de poderes, una legitimidad en la administración (vinculación positiva), un juez o tribunal independiente que dirima los conflictos y un Estado que garantice el Derecho y las libertades fundamentales. Pues bien, tomando estos elementos y examinándolos a la luz del sistema jurídico colombiano, podemos asegurar sin temor a equivocarnos que Colombia goza en cuando menos de un Estado de Derecho, gracias a que propugna por el libre desarrollo de los individuos, la existencia de un poder político o funciones estatales tripartitas y a su vez se encuentra establecido para la defensa de unos derechos de corte fundamental.

Es necesario advertir que la composición del Estado Social de Derecho no va en detrimento de la tipicidad de un Estado de Derecho, es decir, que los contenidos de uno y otro no se excluyen. Por el contrario, es necesario que ambos estén presentes en una perfecta armonía para conformar un verdadero Estado Social de Derecho. Bajo está óptica, se representa históricamente el intento de adaptación del 
Estado liberal burgués a las condiciones sociales de la civilización industrial y postindustrial, con sus nuevos y complejos problemas, pero también con sus grandes posibilidades técnicas, económicas y organizativas. De igual manera, es producto de los movimientos sociales que aclamaban, ya no las esferas de libertad que invadía el Estado en forma de soberano o monarca, sino por el contrario fue imperativo que este ente interviniera al interior de la sociedad y dejara de lado esa indiferencia por las dolencias del pueblo y subsanara la brecha abismal y salvaje que separaban en calidad de vida a unos con otros.

Dicho Estado promueve la realización de la igualdad a través de la procura de un mínimo existencial, una igualdad de oportunidades por medio de un orden económico y social justo. Es pertinente afirmar que el Estado Social de Derecho se encuentra en función de la dignidad humana, que pretende desarrollar el sentido de igualdad en sentido positivo o real, donde el Estado ha de reconocer un trato desigual para los individuaos que por sus calidades humanas exigen un trato diferente, todo dentro de la igualdad; y por último la procura de un mínimo existencial e igualdad de oportunidades como fiel reflejo de la tarea encargada al Estado como portador de un orden socioeconómico justo.

$\mathrm{Y}$ en cuanto a los segundos, es decir, los elementos externos encontramos los siguientes presupuestos del Estado encontrándonos en el primer grupo con:

(i) La Dignidad Humana: El ser humano es fin en sí mismo y todo esfuerzo terreno está referido a su ideal de perfeccionamiento; en este orden de ideas y con relación a este principio fundante del Estado colombiano, es razón de ser constituir un medio idóneo en el cual los asociados puedan extender plenamente sus potenciales vitales.

(ii) Trabajo: por cuanta toda acción externa del hombre encaminada a alcanzar sus fines mediante la interacción y modificación del mundo externo implica la dignificación del hombre por medio de su actividad, es decir, la dignidad del hombre en acto.

(iii) La Solidaridad: es al mismo tiempo, principio fundante, valor, un deber que atraviesa el accionar estatal y el comportamiento de las personas.

(iv) Prevalencia del interés general.

La formula Estado Social de Derecho es en sí misma el principio nuclear del ordenamiento por su posición axial desde la cual permea todo el sistema jurídico (sentido globalizador), porque define el tipo de Estado que Colombia constituye y porque trae consigo la postulación de los fines que persigue el Estado Colomb̈iano.

\section{LA CONSTITUCIÓN QUE PARTIÓ LA HISTORIA DE COLOMBIA EN DOS}

La Constitución Política de 1991 significó para Colombia, entre muchos otros hitos, la consagración de factores y elementos olvidados por el sistema anterior; nació como la panacea que buscaba una Nación y se materializó tras seis meses de debate y consensos al interior de la AsambleaNacionalConstituyente, representante pluralista del pueblo colombiano.

Sin embargo y a pesar de tildarse como uno de los más perfectos textos constitucionales de la época, dicha Carta empezó a sufrir modificaciones y metamorfosis: el Congreso (hablando en sentido general y sin referimos a determinados legisladores en particular periodo) reformó aspectos cruciales del acuerdo político; a ello ha de sumarse las acusaciones provenientes de la doctrina y la oposición, en cuanto a la expedición de leyes contrarías al espíritu de la Carta, y es así como amenizando este descoordinado vals jurídico se encuentra el conflicto entre la guardiana e intérprete de la Constitución: la Corte Constitucional (hija de la nueva Carta Política) y los demás órganos y ramas del poder público. 
Todo lo anterior evidenciado en los continuos choques de trenes, la hemorragia legislativa y el devenir interpretativo, fenómenos que han hecho alzar las voces de defensores y detractores de la Constitución y del Estado Social de Derecho. Los primeros defienden los beneficios de temas como la Acción de Tutela, los derechos sociales, la participación de una Nación _construyendo pensamiento colectivo; mientras sus más enconados críticos, no dudan en acusarla de carecer de una línea coherente de pensamiento, de ser la manzana de la discordia entre los poderes públicos, de ser ambigua e incluso de ser una carta de papel sin aplicación real.

El debate seguirá mientras los poderes públicos, la academia y los grupos de juristas se valgan de la Investigación-para dar respuesta a interrogantes como ¿Ërál es el verdadero espíritu de la Constitución? ¿Hasta donde las modificaciones sufridas por la Constitución en los últimos quince años han menguado la eficacia del Estado Social de Derecho? ¿Es pertinente la aplicabilidad de un Estado de Derecho en Col@mbia? ¿Es real la puesta en práctica de la Constitución de 1991 o se quedó en el papel?.

Nuestro Semillero de Investigación Socio Jurídica Scholla en desarrollo de su proyecto "Análisis del desarrollo del Estado Social de Derecho desde su instauración, y su grado de eficacia posterior en el Sistema Jurídico Colombiano", espera dar respuesta a estos interrogantes con argumentos claros y veraces, sobre la pertinencia y la vigencia del Estado Social de Derecho plasmado en el artículo $1^{\circ}$ de la Constitución Política de 1991. Este debate no debe buscarse en los apasionamientos alrededor de un documento, sino de elementos determinantes que establezcan cual es el camino a seguir, y en ello encontrar los investigadores un reto al cual es imposible huirle.

El presente artículo, busca presentar hipótesis que han surgido, en este proceso investigativo; a su vez compartir las experiencias investigativas mientras abordamos brevemente avances, opiniones y conclusiones de este proceso.

\section{EL ESTADO SOCIAL DE DERECHO: SIGNIFICADO Y BASES IDEOLÓGICAS. SU NACIMIENTO EN COLOMBIA}

El Estado Social de Derecho responde al nuevo modelo socio jurídico, imperante en el mundo occidental desde mediados del siglo XX, con ocasión de la crisis y reflexiones de la posguerra; el Estado Social de Derecho implicó para el constitucionalismo, un paquete de contenido ideológico y filosófico que reúne un conjunto de principios, valores y normas intrínsecos al individuó, a la sociedad y que además integra una reivindicación a los llamados Derechos de Segunda Generación (que nuestra Constitución denomina Derechos Económicos, Sociales y Culturales - DESC).

Este nuevo modelo, si bien permea en el ordenamiento jurídico colombiano con anterioridad (quién no recuerda la Revolución en Marcha de López Pumarejo en 1936), se materializa en todo su esplendor en el año de 1991 consagrado expresamente en la nueva Carta. Entre las innovaciones en el plano axiológico se destacaban entre otras, un extenso catálogo de derechos de segunda generación, fruto de las revoluciones sociales del siglo pasado; una vocación social por parte del Estado materializada en un compromiso de servicio encaminado hacia la satisfacción de unos mínimos vitales: una igualdad real y no la mera igualdad formal de la anterior Constitución de 1886 y el nacimiento de la hoy discutida Acción de Tutela. En su aspecto dogmático la Constitución innovó en temas como la Corte Constitucional (cuya función era 
ejercida por la Sala Constitucional de la Corte Suprema de Justicia), la Fiscalía General de la Nación, el Consejo Superior de la Judicatura (con el objetivo de asegurar la autonomía de la Rama Jurisdiccional) y la Defensoría del Pueblo, todas ellas con el objetivo de ser garantes del equilibrio de poder y la protección de los derechos de los colombianos.

La nueva Constitución se convierte además en estandarte del pluralismo: setenta y dos delegatarios, elegidos directamente por el pueblo colombiano serán los representantes de la nación en la dificil tarea: Indígenas, hombres, mujeres, sectores económicos de derecha y de izquierda, guerrilleros reivindicados, minorías, los partidos tradicionales, y demás, harán parte de este grupo que durante seis meses trabajó en la nueva Constitución. E1 4 de julio de 1991 la pluralidad y la democracia participativa habían triunfado.

\section{LA METAMORFOSIS DE LA PROMESA}

Sin embargo y a pesar del optimismo inicial, la situación no tardó en cambiar: en quince años de vigencia la Constitución Política de 1991 ha sufrido veintidós reformas ${ }^{1}$ que equivalen casi a una cuarta parte del texto inicial; paralelo a esta lenta metamorfosis, el pueblo colombiano en su mayoría, no ha podido disfrutar de dichas aspiraciones de bienestar, equidad e igualdad; las desigualdades económicas, sociales y políticas son de gran protuberancia y el Estado colombiano aún no se compromete de lleno con la tarea que el pueblo le asignó, encarnado en la Asamblea Nacional Constituyente; mientras tanto los índices de desempleo, miseria, grupos que suplantan el papel del estado, migraciones y desplazamiento entre otros escabrosos temas continúan en alza.
Todo ello ha de hallar respuesta en la vigencia o en la pertinencia del Estado Social de Derecho en nuestro entorno jurídico. Por estos motivos nos atrevemos a lanzar cinco arriesgadas hipótesis (haciendo la claridad, que al final de la fase investigativa podemos desembocar en una totalmente distinta):

\section{a. El Estado Social de Derecho no es factible en la realidad actual de nuestro país (Espacio-Tiempo).}

Esta hipótesis no es tan novedosa y ha sido recogida por respetados tratadistas, constitucionalistas y juristas desde la misma transición constitucional de 1.991. Según ésta controvertida teoría, el Estado Social de Derecho sistema de gran trascendencia e impacto en la Europa de la Posguerra y de gran calado en la reivindicación jurídica del Siglo XX (fenómeno que distintos autores denominan como el regreso al antropocentrismo y no al institucentrismo), sería inaplicable en nuestro país y en nuestro siglo.

Los argumentos que llegarían a soportar esa tendencia serían la existencia de una cultura que además de ser plural y multirracial, carece de una unidad nacional y de un respeto a la normatividad sin que medien los elementos de coacción y coerción de los que hablan juristas como Kelsen. Ésta tesis tendría asidero igualmente en aquellos críticos de la inclinación de la Corte Constitucional a tutelar derechos que implican previamente un desarrollo económico. Según ésta posición, las consecuencias de esta protección indiscriminada ( $\sin$ tener en cuenta consideraciones de índole presupuestal) llevaría al Estado a convertirse en una utopía de esquizofrenia, donde una situación está plasmada en el papel y otra se lleva a cabo en la práctica. Igualmente daría lugar a un fenómeno que distintos constitucionalistas ya han

\footnotetext{
${ }^{1}$ Solo una de ellas con intervención directa del constituyente primario.
} 
criticado desde tiempo atrás: "el Gobierno de los Jueces" , donde los límites de actuación y competencia de los tribunales constitucionales serían inexistentes. Para los partidarios de esta hipótesis, ello sería plenamente comprobable en la incapacidad del Estado para satisfacer plenamente a todos los postulados consagrados en la Constitución; de resultar comprobada esta hipótešis en el presente proceso investigativo el Estado Social de Derecho sería inaplicable en el contexto espacio-temporal colombiano.

\section{b. El Estado Social de Derecho sólo se materializará cuando el cambio generacional permita que las autoridades y los jueces ordinarios sean concientes de sus efectos}

En ésta hipótesis siguen militando quienes piden tiempo para alcanzar todos los valores y normas consagradas, quienes acusan a los retrógrados vicios heredados de la Constitución anterior. Dicha tesis tendría su fundamento si las autoridades públicas, el legislador actual y los jueces ordinarios (a los que la misma Carta magna elevó a jueces constitucionales al darles competencia para conocer de la acción de tutela), siguen estando formados académicamente bajo los conceptos y métodos interpretativos de la centenaria y desaparecida Carta Política de 1.886. Por ende aún no comprenden la responsabilidad que implica el cumplimiento de un Estado Social de Derecho y la materialización, protección e importancia, no solo de los derechos de primera generación, sino de los Derechos Económicos, Sociales y Culturales (DESC), los cuales juegan un papel predominante (para algunos excesivo) en el nuevo constitucionalismo colombiano.

Sin embargo detractores de ésta tesis encuentran los argumentos en que los Magistrados de la Corte Constitucional también se han formado bajo los parámetros de la antigua constitución y sin embargo han desarrollado en un sin número de casos, una tendencia protectora hacia los derechos, aún soportando acusaciones de desequilibrio de poder y de invadir órbitas de otras ramas del poder público.

Si pudiese comprobar que esta tesis es verdadera será inevitable encontrar que en las Facultades de Derecho irá en aumento una elaborada tesis que implique la promoción ineludible del "Nuevo Constitucionalismo", como ya la denominan diferentes autores de diversas escuelas jurídicas , mientras que en el Capitolio Nacional, los estrados judiciales y los tronos de poder agonizará ese viejo sistemaa interpretativo que gestó el mundo desde la Revolución Francesa, denominado Estado de Derecho y que hoy muchos desechan por considerarlo de páginas de la historia manchadas de muerte y desgracia, como la Alemania nazi ó la España Fascista.

Y si la Carta de 1.991 es la plena materialización de los postulados del Estado Social de Derecho, y lo único que nos resta es esperar, no habría coherencia en el fenómeno reformista que ha invadido anuestropaís. ¿Quénosllevó a reformar temas tan importantes como la elección del ejecutivo, los periodos de mandatarios locales, las competencias constitucionales de la Fiscalía o la extradición?

c. El Estado Social de Derecho está vigente: las reformas constitucionales, la promulgación legislativa y los grandes pronunciamientos de la Corte son el perfeccionamiento del nuevo sistema y no van en detrimento del mismo

Aunque para muchos puede parecer iluso defender esta hipótesis, es necesario considerar la posibilidad (alejada de cualquier pragmatismo

\footnotetext{
${ }^{2}$ Ver entre otros: LOPEZ DAZA, German Alfonso. La justicia constitucional colombiana: ¿Un gobierno de los jueces? Neiva: Editorial Universidad Surcolombiana, 2005. NUÑEZ, Antonio José. Manifiesto por una justicia constitucional responsable. Bogotá: Legis, 2005. MORELLI, RICO, Sandra. La Corte Constitucional: ¿Un legislador complementario? Bogotá, Universidad Externado de Colombia, 1997.
} 
político o cualquier consideración personal de índole subjetiva) de que las reformas que ha sufrido la Carta Política en los últimos quince años (porque además es de destacar que sufrió reformas, casi desde el mismo instante de su nacimiento) han ido en consonancia con el espíritu del Estado Social de Derecho; plena prueba de ello sería la aprobación del examen meticuloso que la Corte Constitucional hizo de los Actos Legislativos demandados al calor de la eterna discusión de hasta donde está facultado el Congreso investido de la potestad de Constituyente Secundario, para reformar la Constitución (recordar numeral 1 del Artículo $241^{3}$, que establece la potestad para revisar y evaluar los Actos Legislativos solamente por vicios en su procedimiento).

De ser comprobada esta hipótesis; conflictos entre las ramas del poder e incluso entre órganos de una misma rama, como por ejemplo la lucha entre el legislativo y el ejecutivo, las potestades del gobierno o el choque de trenes, serían solamente fenómenos razonables que tienen lugar en cualquier sistema que ha tenido una evolución positíva como sería el presente caso.

Esta hipótesis sin embargo deja sin respuesta interrogantes de gran importancia como la impracticabilidad de muchos de los derechos y valores consagrados en la Constitución como es el caso del Derecho a la Paz ${ }^{4}$, sus partidarios acuden a problemas externos para justificar su silencio incomodo, por ejemplo la violencia, la ineficacia de la Justicia, los índices de pobreza, etc,y losmás osados no dudan enacudira la eterna discusión entre economía y derecho, acusando a la primera de todos los males existentes y futuros. Sin embargo, tampoco estas respuestas satisfacen plenamente los interrogantes en torno a la pertinencia y vigencia del Estado Social de Derecho en Colombia, ya que nos sumergen de nuevo en la contradicción permanente entre realidad y Constitución, eterna dicotomía que tiene como índice la Acción de Tutela; porque es necesario, detenernos aquí, para contradecir en el curso de esta investigación consideraciones de importantes académicos y suprimir juristas al decir que los altos niveles de Acciones de Tutela presentadas ${ }^{5}$ y revisadas por la Corte, en uso de sus atribuciones constitucionales ${ }^{6}$, no son prueba de la eficacia de nuestro tribunal constitucional, como afirman incluso algunos de sus miembros ${ }^{7}$, sino de la mencionada dicotomía realidad- Carta Política; "ello, por consiguiente se opone a esta hipótesis.

\section{d.ElEstado Socialde Derecho estásufriendo un paulatino desmonte desde las ramas del poder con fines netamente económicos o políticos o simplemente por alcanzar metas particulares}

Quizá la más sugestiva de las hipótesis presentadas al tenor de este proceso investigativo seria: La ilusión materializada de una Nación por alcanzar la tan anhelada paz mediante la participación de todos los estamentos de la sociedad y la búsqueda del consenso y no de las mayorías o la maquinaria política bipartidista imperante, habría sufrido una implacable persecución por parte de sectores económicos, políticos, los cuales encarnados en los poderes públicos se habrían dedicado a darle una estocada al documento promulgado por la Asamblea Nacional Constituyente el 4 de julio de 1.991 en el salón de la Constitución. Por ello la ola reformista y sus intentos perdidos (que suman 340), la jurisprudencia emanada de la Corte Suprema de Justicia y el Consejo

\footnotetext{
${ }^{3}$ Constitución Política de Colombia (1.991).

${ }^{4}$ Articulo 22 ibídem.

${ }^{5}$ Alrededor de 1.400 .000 según relatoría del Corte Constitucional.

6 Numeral 1, Artículo 241 CP.

${ }^{7}$ Entrevista al Dr. Manuel José Cepeda Espinosa, Magistrado y Ex Presidente de la Corte Constitucional. Ámbito Jurídico (Edición julio de 2.006)
} 
de Estado (máximos tribunales de la justicia ordinaria y la jurisdicción contenciosa) y la hemorragia legislativa (que en Colombia en 15 años suman aproximadamente 1.020 de las cuales unas reforman a otras) serían el intento indiscrimirado de terminar con el espíritu de la Constitución; pruebas de ello se podrían resumir por montones en temas tan relevantes como el difícil acceso a la salud o a la educación.

Sin embargo, y aunque sea esta tesis la que mayor número de partidarios tiene, no deja de generar inquietudes, como por ejemplo: ¿Cómo explicar la flagrante violación del espíritu del Estado Social de Derecho en cabeza del ejecutivo y del legislativo, los cuales son elegidos popularmente? Y a su vez ¿Cómo explicar la enconada defensa de los mismos derechos en cabeza de la Corte Constitucional, compuesta por juristas que a su vez son elegidos por el Senado de ternas enviadas por la Corte Suprema de Justicia, el Consejo de Estado y el Presidente de la República?

Es evidente que lá corroboración de esta tesis implicaría descubrir un retroceso en materia jurídica de grandes proporciones; concluir que algo que existió está en camino de perecer suele ser mucho peor que corroborar la inexistencia de dicha realidad. Estaríamos frente a una crisis en materia constitucional sin precedentes en la historia constitucional colombiana, ya que ni la misma Constitución de 1.886 en sus 105 años de historia sufrió tantos ataques, ni tantas reformas como la presente Carta Política.

\section{e. Estado Social de Derecho y Desarrollo Económico: ¿dos realidades que no pueden ir de la mano?}

Podemos afirmar ésta hipótesis investigativa esbozada por múltiples tratadistas, principalmente economistas, que han analizado el desarrollo de las naciones desde el Estado liberal hasta el Estado benefactor, haciendo énfasis en la imperceptible pero trascendental transición del Estado de Derecho al Estado Social.

Si aplicamos esta hipótesis a la situación colombiana, es necesario partir del análisis de las discuciones realizadas en la Asamblea Nacional Constituyente, con relación a la implantación del Estado Social y todo lo que ello implicaba: la consagración de importantes derechos de todo orden, la adopción de la acción de tutela (hija digna del derecho de amparo español y a su vez del verfassungsbeschwerde alemán); el fundamento de esta hipótesis es que el Estado Social de Derecho jamás podrá ir de la mano del desarrollo económico de una nación; por eso es el modelo típico,jimperante en los paises subdesarrollados o tercermundistas; un país (según esta hipótesis) no puede basar su orientación jurídica y política en un desequilibrio en favor de los más necesitados porque iría en contravía de otros postulados económicos. Ello sin embargo, no significa un menosprecio declarado a las desigualdades económicas, políticas y sociales latentes en nuestro país, sino una negación a la implantación de este modelo social basándose en e! principio lógico de que "sin dinero no puede haber satisfacción de necesidades básicas insatisfechas". Se requiere primero corregir los errores y las falencias económicas, fortalecer los principales sectores nutriendo al país con producción para hacerlo sostenible (basándose en los principios smithsonianos y ricardianos de las Leyes del Mercado y la no intervención de los órganos del Estado -ni siquiera los judiciales- en los temas económicos); sobra decir que dicha tesis tiene contradictores acérrimos, obviamente defensores del modelo y que no vacilan en esgrimir argumentos típicos de Marx para atacar a los economistas.

Es necesario reiterar que los exponentes de la quinta hipótesis no atacan el Estado Social de Derecho; lo que ocurre es que defienden una fase anterior que consolida las bases económicas, mientras manifiestan como prueba de su teoría la contradicción permanente entre Estado Social de Derecho y Desarrollo Económico?. 


\section{LOS DOS LADOS DE LA MONEDA}

Es imposible abordar el tema de la pertinencia y la vigencia del Estado Social de Derecho sin ver en realidad losados grandes grupos alrededor del proceso constitucional nacido en 1990 a raíz de un movimiento estudiantil "la séptima papeleta": sus enconados defensores y sus implacables críticos. Este debate ha vuelto a renacer con motivo de la celebración de cristal (quince años) de la polémica Carta.

Los primeros no dudan en argüir los indiscutibles beneficios que trajo en comparación a la obsoleta constitución de 1886, como la aparición de la acción de tutela como alternativa de protección los derechos del individuo, el nacimiento de la Corte Constitucional independiente de la Corte Suprema de Justicia (máximo tribunal de la jurisdicción ordinaria), la Defensoría del Pueblo y la Fiscalía General de la Nación; sin embargo, los segundos no vacilan en afirmar que la Constitución Política de 1991 carece de una línea coherente y única de pensamiento y que entre miltiples contradicciones se puede citar la consagración de un Estado
Social de Dertecho y de wa eomanle ahiers basada en la libre emprese la plumilibad $y$ di consenso lo que en boce de sus dementres convierten en el desorden y en la wesenca de unos principios rectores que agrupen de $m$ menta armónica la parte dogmática y la parte organica de la Constitución; prueba de ello sería una organización incoherente del sistema jurídico colombiano donde el equilibrio de poderes implica que la elección de los órganos del poder público sea un "carrusel de favores" en un Estado donde corrupción y el clientelismo conviven con la política colombiana.

Es necesario para la investigación, ahondar en las entrañas del proceso que la Asamblea Nacional Constituyente realizó, de tal manera que logremos interpretar el espíritu de la Constitución. Respecto a este punto específico, el conflicto parece tampoco tener fin. La interpretación del Estado Social de Derecho es disputada por el legislador el cual tiene la tarea delegada del pueblo soberano de hacer la ley, reformar la Constitución y ejercer el control político; la Corte Constitucional, guardiána de la integridad de la Constitución y el juez ordinario, quien mediante la Acción de Tutela ostenta un poder del que antaño carecía.

\footnotetext{
${ }^{9}$ Este interesante argumento se discute con ocasión del Caso Francés, que al apartarse de sus tesis defensoras del Estado Social, de nuevo levantó la cabeza económicamente hablando, y salió a flote después de la Crisis de la Posguerra. E1 caso francés y el caso inglés. Compendio de Economía y Derecho. UNIVERSIDAD DE PADUA. Segunda Edición
}

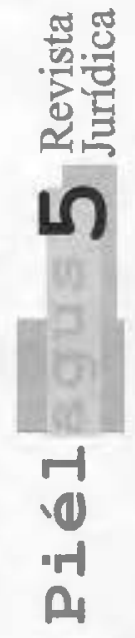

